\title{
The dislocation of composition: architecture and eco-sustainability
}

\author{
A. Sichenze, I. Macaione \& M. I. Insetti \\ Department of Architecture, Planning and Infrastructures for Transport, \\ University of Basilicata, Italy
}

\begin{abstract}
This paper deals with the problem and experiences of "ecological hetero-genesis of the ends", within an architectural context, by defining the 40 year old trajectory of the ecological approach to architecture in a partial and critical balance based on the main results obtained. It results being a context of successes and insufficiencies from which a decisive step in the direction of a phenomenological architectural practice of eco-sustainability can be taken, through tests on both the scale of the nature-city as well as "residential dislocation". The paper deals with these new experiences in order to show the visions of projects and initial realisations.

This research deals with the description of a phenomenological approach to design by two new procedures of direct union in relation with the beauty of sense of limit in architecture. Where the sense of limit is extended both to the availability of the resources and the concept of balance of the ecosystem in which architectures are immersed.

Keywords: nature-city, phenomenology, eco-sustainability, architecture, limit.
\end{abstract}

\section{Introduction}

Following about 40 years of planning and applications, eco-sustainability has decisively become an intentional part of architectural design and testing of new areas and urban parks aimed at the idea of the sustainable city (e.g. Vauban and Rieselfeld, Freiburg im Breisgau, Germany; Solar City, Linz, Austria; Hammarby Sjöstad, Stockholm, Sweden; 119 Houses on Hagen Island, Ypenburg, Holland; Benny Farm Reconversion, Montreal, Canada).

There are no projects relating to entire eco-cities, with only China having planned 400. From the organisation of numerous exhibitions dedicated to 
bio-constructions as well as the study of publicising the sector, it is clearly evident that Europe has a large pool of techniques, regulations and tests of various types capable of finally overcoming the old idea of sustainability, going beyond the objectives set in Kyoto.

However, even though we are now finally equipped with everything, both technologically and administratively, required to establish a productive culture of bio-constructions, we realise that along with an evident global political and managerial delay [1], there is also a cultural one.

It is both in the participation of the population and society, with the causes having been studied at international conferences [2], as well as the training of architects and town-planners who cannot define the normal procedures of a "sustainable situation", on the scale of both places as well as a "global ecology, connecting local and global [3].

There are many interconnected reasons for these delays, but they can essentially be traced back to the problem which phenomenological philosophy has already dealt with in depth, while in Italy, it is connected to architectural experience.

If the world of ecological representation, also scientific, and production creates languages, pre-constructed judgements and partial visions of separate aspects of things, of all the things, including natural things, means that even ecological science cannot escape their specific difficulty.

They are therefore based on "structures which connect", e.g. eco-systems. In reality, they are applied through objects.

However, even though they collect, capture and calculate single relations with the natural world, they paradoxically separate them from these and any other objects, disconnecting everything. Therefore every object of the bio-construction is added to the others without interconnecting or integrating them into a whole environment.

When faced with this difficulty, architecture adopts a phenomenologicaldesign approach which "suspends the judgement (l'epochè) on the sustainability offered as a scientific fact.

It proposes a return to the ecological phenomenon as a lived world.

All that we know about ecology and sustainability starts from our experience of the world in which ecology is only a secondary experience, without this direct relationship with the things and the world, all our "scientific bio-constructions" mean nothing.

Our existence and behaviours towards the resources of nature sustain the world as well as sustainability itself.

It is therefore a return to the same things as well as the same phenomena of nature within the city.

It implies, as asserted by Maurice Merleau-Ponty, that "returning to this world anterior to the knowledge of which knowledge always talks about, and in relation to which every scientific determination is abstract, significant and dependant as the geography in relation to the landscape in which we originally learnt what a forest, a field and a river are" [4].

These things are themselves "pre-objective and anti-predictive". 
It therefore means not using the scientific, ecological and bio-constructive knowledge which we now have, but simply not giving them as acquired. On the other, it implies a return to a world distant in time, the original experience is considered to be behind today's world and in reference to the appearance of the sense of those things today.

The world, in a phenomenological sense, is not the being in a pure state but "the sense which transpires from and to the intersection of my experiences as well as those of others, thanks to the grafting of one to the other. It is therefore inseparable from subjectivity and inter-subjectivity, which realises their unity through the revival of my past experiences through my present experiences, through the experiences of others in mine" [4].

Two new procedures of direct union have been proposed upon which technoscience and ecology have based debates, theories and calculations of the constructed environment 1) genetic phenomenology, in other words the "discovery with awe" of existing Nature-Cities [5] and 2) constructive phenomenology, the designing of a new Nature-City today, as the "ecological dislocation" of an architecture which creates in every part the initial relations and the physical conditions of existence of its "world of life".

An essential idea of the eco-sustainability of development is therefore becoming part of the design and realisation procedures of architecture which in paying attention to the "slow signs of what escapes every calculation" recognises in itself all that is not an expected and usable object, in the relation with nature. It can still create awe. However, not in the sense of the star architects. Instead.

An architecture stupefies in which being beautiful is both the sense of the limit, extended to the availability of the resources of the ecosystem in which it is immersed.

An architecture stupefies in which, in the transcending way, in a dislocating way, in the city, it re-generates without stress the relation with nature, renewing the resources.

An architecture stupefies in which the world of life, passing through the objects produced by ecological industry of sustainability, rediscovers the traces of the things included in an original ecological complexity which is never already in departure. And this should never reveal itself, allow itself to be seen, apart from by itself, but in the sense of ecological richness in which "everything is connected to everything".

In this sense, there is no "eco-architecture".

There are architectures which, every time in their work, still allow manifestations of itself the ecological complexity of the regeneration of the Nature-City, in relation with a new (always new) sense of the limit which can be transcended only in a constant dislocation process.

\section{The project of architecture between place and non-place: Alethèia}

An experience, transmittable in this sense, is carried out by us designing a park known as Alethèia (Masterplan of the park project Alétheia coordinated by 
A. Sichenze within C.A. Fosci, M.I. Insetti, G. Izzi, M.R.A. Piro. Projects supervised by: A. Sichenze, M. Lavecchia, I. Macaione, E. Micelli, A.M. Puleo, A. Telesca, V. Telesca with specialised degree thesis by S. Gramegna, M.I. Insetti, C. Miroballi, F. Romano).

It is worth highlighting the project only for the reason that it assumes the exceptional nature of an essay written aside the architectural works of art.

What it tells of the project however it does not say, and therefore has to be anticipated, is the fact that the tourist route through the park is conceived as a continual transcendence of the limits of the experience from one place to another of the Nature-City: from the entrance to the exit, designing a spatialisation in time (where what space tends to substitute time) in the search of "where and how to be" (ecological in the future of the world), in a continual dislocating experience. However, what it wants to dislocate here is the experience itself of the order of an eco-sustainable world of the Nature-City, heterogeneous withy the aim of bio-climatic strategies and never carried out by itself, continually readjusted with respect to new relations of reciprocity between the places that it constitutes along the route.

At the end of this journey of the search of a uncovered sustainability, lived and tested, it can be asked whether it is still possible to live differently, living an eco-sustainable also subjected to a continual dislocation (see also Benoît Goetz, La dislocation, Architecture et philosophie, Editions de la Passion: Paris, 2001). Then returning to the unsustainable city, it is possible to imagine that whether an eco-sustainable rehabilitation can be carried out, this can not occur in such a discontinuous and dislocating process.

The human experience of life in a Nature-City made by the host as well as the visitor of the aforementioned park begins at the Entrance, passing through the confining limits of the park, a winding wall which accompanies the visitor until entering a hypogean structure, the Door of the falcon (1), which opens south and looks over the park from above. It is a project which depends on the welcoming culture of the woman as well as the sense of a rocky architecture which takes full advantage of the bio-climatic advantages of all that is within land. The hypogean space is therefore presented as all involving, soft, fluent, well-looked after, ready to welcome either one or the other. The origins of richness are represented in this place, seen in the multiple diversity of the visitors, the guests and the figures which are all united again in the park: the circle, the ellipsis, the cross and the sinusoid.

The second step induces the visitor to abandon their vehicles, upon passing through the Archipelago 1 (3), a discontinuous system of parking areas which try to hide themselves among the small hills, trees and shrubs. In this way, while on road level, slightly sloping, the vehicular impact is reduced, breaking it up in part, while at the level of the hills, the trees with their thick leafy branches create a continual eco-vegetation. There are open sites on the insular areas where small groups of people can be with each in order to either display works of art or start an eco-museum which will eventually be developed throughout the park as well as inside the grottos. 
Then you enter the bowels of the land, in the Symposium (2): the collective space par excellence in which banquets, shows, conferences, cultural and artistic meetings, dances are held, where the guest has a collective experience associated to the representation. In the architecture of this construction the plurality of the various ways of "being" of the people as well as the points of view, in the representation of the world, is set immediately under the ground, reducing the architectural impact with the landscape, while several other elements emerge in the sunlight.

Re-conquering the light, ascending towards a sacred panorama, the Annunciation (4), from where in a sense a much wider panoramic view can be seen and being, in the other, seen from afar by many other places within the park.

The visitor subsequently reaches the Hamlet (5), a round area, based on the rehabilitation of a row of houses, integrated with new constructions which includes a space nearby where a rural-urban experience can be had, in contact with the traditions of the Nature-City, in other words the re-generation of the body, in close contact with water (present in the areas of rural architecture of water, known as Gymnasium (7), with a swimming pool, gym -and beauty-farm-, stoà. The area should deal with the problem of reducing the maximum impact, in a delicate point for the equilibrium of the park, in which all the elements should be considered and contained. The various pools have long looked for the most suitable position, dimension and character, finally aligning with the slope, with the solar orientation and the scenes of the landscape, with the fruits of the land as well as the gastronomy of the Nature-City. The visitor can either relax on the terrace or feast in the Banquet Hall, either staying only for a meal or having a particular residential experience in the ecological houses of the Hamlet or Island 1 (6), where there are several different types of accommodation, including that of maximum individuality in contact with the landscape.

The maximum aspiration of civil insularity of a millenarian culture of nature is expressed here, inspired by monastiscism, proposed and revisited within a modern context. The project is conceived taking into consideration the volumetric and highly consistent nature of architecture in Basilicata, which relies on noteworthy masonry, re-proposed within a bioclimatic context, in constructive devices, known as thickness walls. These are "nature containers" (water, earth, sun, ecological plants) which intertwine the tissue of a type of micro-urbanistic ecology.

From the hamlet, the visitor can walk as far as the Agorà of the market (8), a place of re-departure and initiality of a city which regenerates itself, becoming enriched with things arriving from the outside, coming from the "knowledgetaste" of the productive context of its territory as well as through the opening of the relations of the world with other Nature-Cities, in which we learn of other ways of knowledge and how to live on its own territories of nature. The tourist appreciates the multiple products of the world of the Nature-City.

Above the ridge, there is the "City of horses" (9), which cannot be visited but can be seen from a distance. Passing through the "Green Way", a linear ecovegetative and hydro-morphological system, the visitor then continues the walk 
until reaching the small road-side hamlet of THiasos (10). A complex created as a prestigious residence for cavaliers and clubhouse, where a selection of society and products of the Nature-City meet: craftsmanship, music, club, places for engaged and married couples.

The wedding tower, the last building of the road-side hamlet, looks over Archipelago 2 (11), the centre of the park.

Archipelago 2 is dedicated to the representation of peace and sustainability, as well as the freedom of nature. It is made up of three very close "islands", where in the recent past horse races were held.

The areas, on different levels, belong to a unique system. They have now been recuperated and destined to leisure activities.

The first, Apeiron, the typical open space of a park, is dedicated to leisure activities for everyone.

The second island, Paideia, the city for the young, is a park, a leisureecological park, dedicated to games of peace to regenerate the Nature-City.

The third island, Eleutheria, subject of an eco-vegetative rehabilitation, situated on the highest level, is a mini wood, also dedicated to leisure activities, in preparation of the experience to be carried out in the Big Wood.

Having re-conquered freedom, beyond this centre-limit the park offers three more areas of constructed environments which, in addition to the functions of service and residence, proposes three themes for reflection. Agon (14), the last "island" of the archipelago, a small stadium for horse-jumping contests, with all the required services, proposes the theme of competition.



Figure 1: The integrative structural connections acting within the inside of the dynamics of the park. Form the top: the TISSUE type, the JOINT type and the FASTENED ZIP type. 


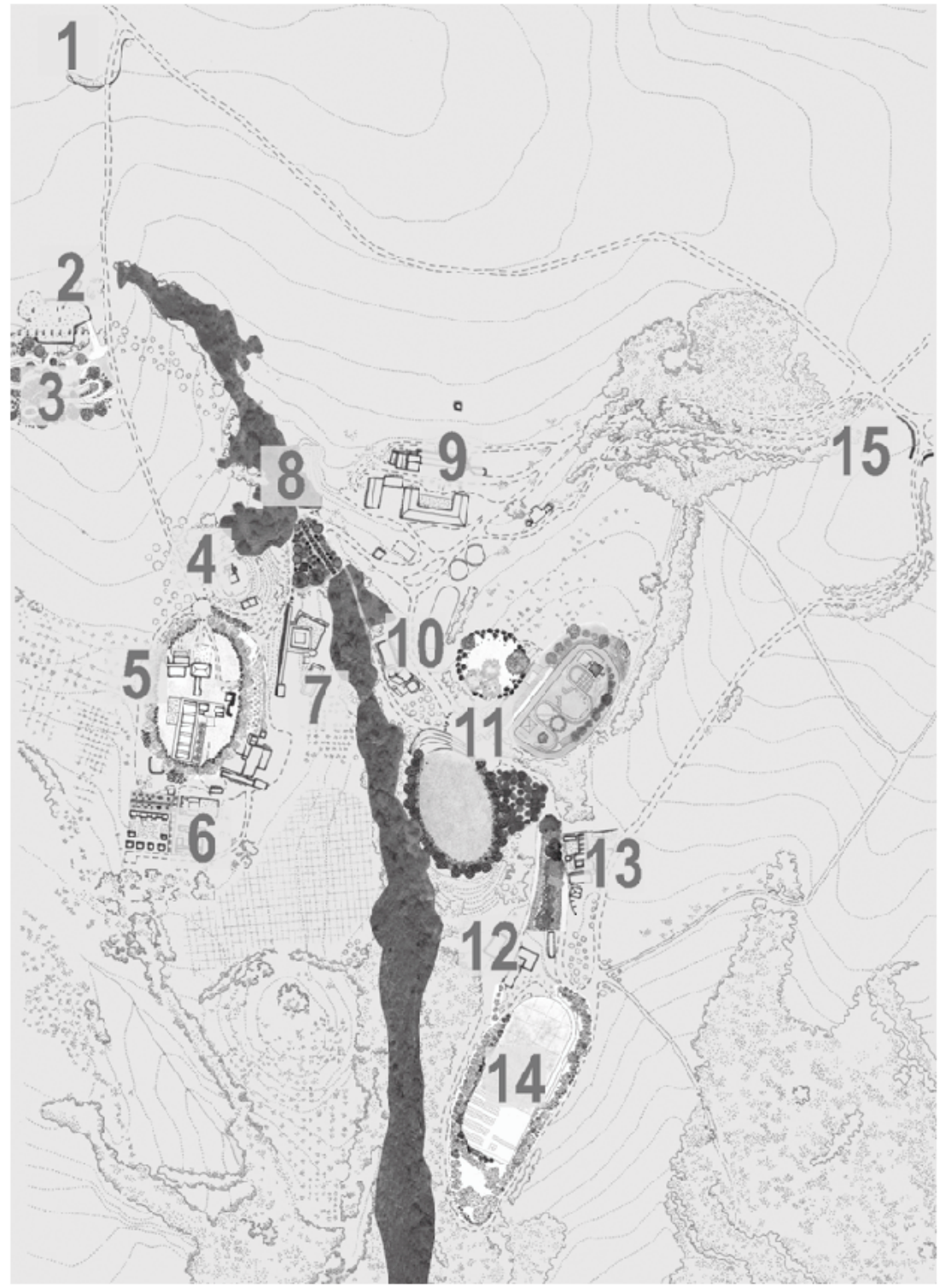

Figure 2: $\quad$ Alétheia, plan and, in the next page, the projects. 
114 Eco-Architecture II

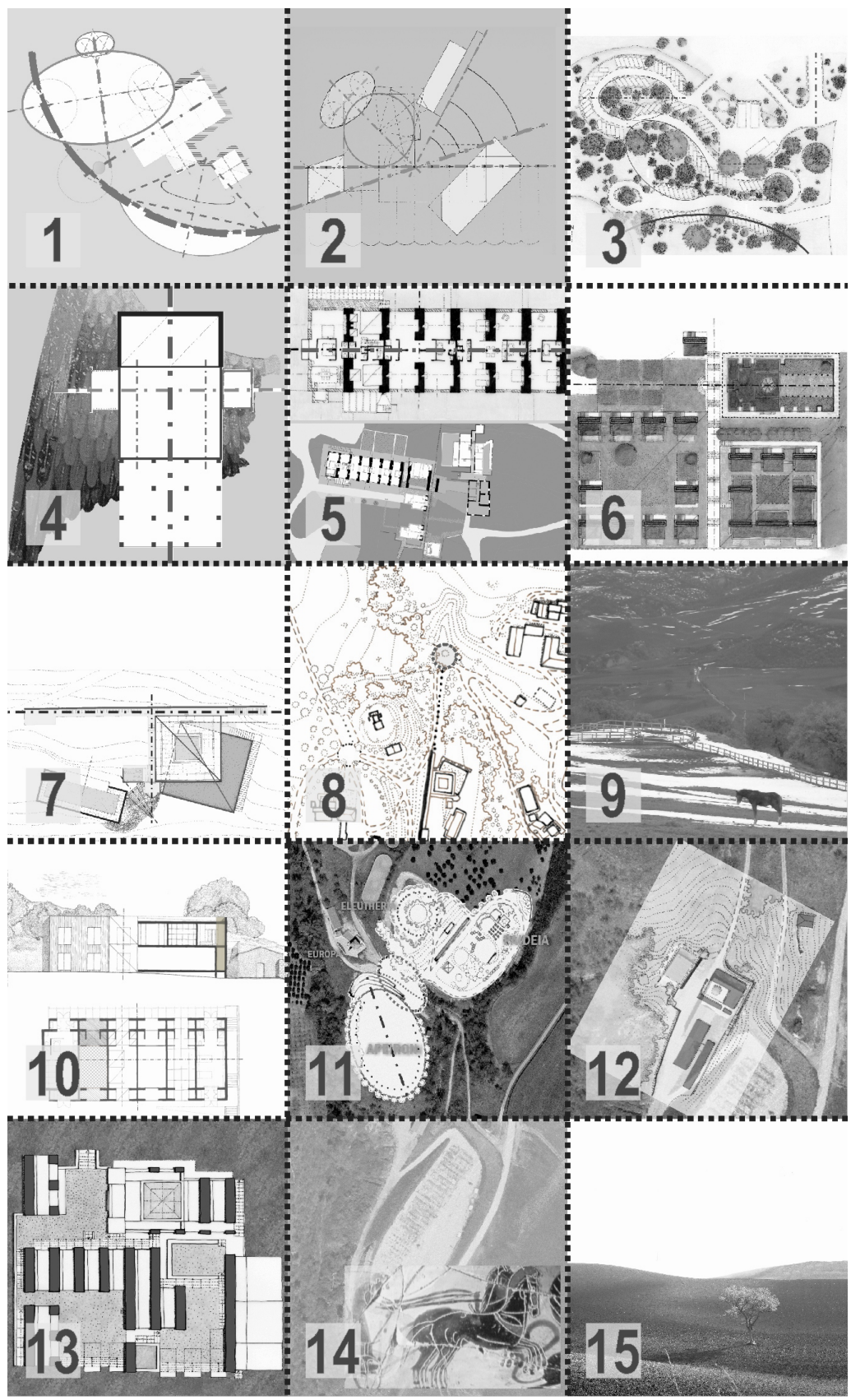

Figure 2: $\quad$ Continued. 
Island 2 (13), the small ecological hotel, surrounded by the memory of a typical architecture of the Country-City, on the model of the Charterhouse, ready to dialogue with a ruin re-assigned to a "postal-station" and which proposes the theme of the relationship with nature as well as the ruins of history, in the horsejourney.

Whereas in Meriston (12), a space of "supplies" for the future which is the basis for a Hostel, young people can have the experience of the frontier, where everything is possible, but with the knowledge that the future is strewn with ruins.

Finally, there is the Remetiri (15) sculpture: taking its measurements from the same in the journey for the search for the truth which helps to live on the scale of the Nature-City, signifying that after the experience, we have to look at ourselves in order to understand where we are, in relation to the places visited and the discovery of the truth which helps live.

It is only on this scale that every individual can overcome his own limits.

In conclusion, it is worth highlighting that the integrative structural connections acting within the inside of the dynamics of the park are characterised by the following three types: the TISSUE type, which tends to propose itself as a resistant to form complex, in which the whole sustains a unique form of interconnection and the elements, almost identity, are worth the prototypical quality which sustains it; the JOINT type, which is configured as a composition between parts with different characteristics in the which the ideas of everyone tends to be absorbed by every single part which carries out a different role from the others; finally the FASTENED ZIP type, which can consists of repeated and different elements set out linearly and is suitable in the rehabilitation of the existing.

It is also worth noting that the constitutive elements of each type act in function of the constituent relation not only between the component parts but also among the latter and everything.

\section{References}

[1] Macaione, I., (eds). Architettura e Management della Città-Natura, FrancoAngeli: Milan, 2007.

[2] Sichenze, A., Macaione, I. \& Insetti, M.I., The discovery of the nature-city and the re-generative strategies. Sustainable Tourism II, eds. C.A. Brebbia \& F.D. Pineda, WIT Press: Southampton and Boston, pp. 95-104, 2006. Sichenze, A., Macaione, I., Lavecchia, M., Piro, M.R.A., Lavecchia, M., Fosci, C.A. \& Insetti, M.I., From cultural heritage to sustainability: architecture and the nature-city. Proceedings of the 7th European Conference "SAUVEUR" SAFEGUARDED CULTURAL HERITAGE Understanding \& Viability for the Enlarged Europe, vol. I-Papers, ITAMARCCHIP Centre of Excellence: Praga, pp. 303-313, 2007.

[3] Insetti, M.I., Book abstract and possible elaboration of the research. Architettura e Management della Città-Natura, eds. I. Macaione, FrancoAngeli: Milan, pp. 244-247, 2007. 
116 Eco-Architecture II

[4] Merleau-Ponty, M., Fenomenologia della percezione, Studi Bompiani: Milano, 2003.

[5] Sichenze, A. \& Macaione, I., La città-natura per un turismo sostenibile: fenomeni e strategie, in Il progetto sostenibile, 14, pp. 11-19, 2007. 